\title{
ANTE-PARTUM THROMBO-EMBOLISM
}

\author{
J. J. TAYLOR, M.B., B.S. (Lond.) \\ Senior Registrar in Clinical Pathology, United Birmingham Hospitals.*
}

WHILST thrombo-embolism is a well recognised complication of the puerperium, ante-partum it is rare. No mention of its management is to be found in standard textbooks. Despite controversy concerning the value of anticoagulant treatment in arterial thrombotic disease, the efficacy of this therapy in venous thrombo-embolism is now well established. The apparent rarity of this condition in the antepartum period and its high mortality rate, coupled with the special hazards of anticoagulant treatment at this time prompt this report of two cases, in one of which the outcome for both mother and baby was favourable and another where post-mortem cæsarean section was employed.

\section{Pathogenesis of Thrombo-embolism in Pregnancy \\ Changes in the Blood}

Formed elements. During pregnancy both plasma volume and red cell mass increase. From about the third month onward mild leukocytosis may be found especially in primigravidæ. No consistent change in platelet count or morphology occurs. The result of these changes is an increase in the total circulating number of all formed elements.

Coagulation factors. Factor 1 (fibrinogen) rises during the first eight weeks and remains elevated throughout pregnancy. Whilst factor II (prothrombin) may fall a little in the later months there is a decreased titre of antithrombin and fibrinolysin. Due to the increase in plasma protein in pregnancy there is thus an increased amount of circulating coagulation factors.

\section{Changes in the Vessels}

Varicose veins are commonly seen in pregnancy, at which time the vulva, broad ligaments and uterus may be severely affected. Within the pelvis marked increase in vascularity occurs and the cardio-vascular system as a whole exhibits a hyperdynamic state. It thus seems unlikely that intimal hypoxia can develop in normal vessels; where there is local pathology however the increased circulation rate may be

*Present address: Dept. of Haematology, Queen Elizabeth Hospital, Birmingham, 15. deleterious leading to eddy formation, the central core flowing rapidly on, and the peripheral laminæ suffering varying degrees of obstruction. Such a hypoxic condition of the intima predisposes to thrombus formation, damaged intimal cells having thromboplastic activity (O'Brien, 1959).

Experimentally, blood between venous ligatures remains fluid, but when veins are isolated from their own vascular and nervous supply thrombosis occurs and is preceded by changes at the intimal surface. By a silver nitrate technique with flattened intimal preparations it has been shown that under such conditions platelets adhere to and outline the intercellular borders. Subsequent viscous metamorphosis leads to the formation of a mass of platelets and fibrin which may be accompanied by dissolution of the endothelial wall (O'Neill, 1947).

Aggregation of polymorphs and monocytes $\overrightarrow{0}$ around the platelet clumps leads to the formation of the white-headed or "coralline" (coral-like) thrombus, a description derived? from the ramifying nature of the structure so formed. From this further strands of fibrin extend to enmesh red cells and so is formed the red-tailed thrombus (Poole, 1959). Detachment of the latter may give rise to clinical attacks of embolism.

\section{Stasis}

Conclusive proof of stasis in the legs during pregnancy has been provided by the use of radio-active sodium (Wright, Osborn and Edmunds, 1950). Several factors contribute, among them the decreased action of the diaphragmatic pump, diversion of blood through the placenta, the obstructive effect of the increased volume of pelvic venous return where it enters the iliac veins, and local uterine pressure on the intra-abdominal veins, including the inferior vena cava (Burwell, 1938; Kerr, Scott and Samuel, 1964).

When the blood stream slows platelets become more plentiful in the peripheral slowermoving lamina than in the central core; in this position they are more accessible for attachment to the intimal surface, a sequence of events which has been demonstrated cinematographically (Witte and Schricker, 1958). 


\section{Uterine swelling}

Thrombosed pelvic veins may be seen at operation in the presence of uterine swellings, local sepsis and in pregnancy. Despite the frequency with which leg vein thrombi can be demonstrated in fatal cases of embolism it is however likely that emboli can and do arise from the pelvic veins in the absence of clinical or autopsy evidence of leg vein involvement.

\section{Role of the Placenta}

Trophoblast has a powerful proteolytic action, and in normal pregnancy deep invasion of decidual and myometrial tissues occurs. Microscopically, penetration of maternal veins is common, and from time to time portions of such tissue may suffer detachment coming to rest in the lungs. Such trophoblastic embolism occurs more frequently as pregnancy proceeds (Attwood and Park, 1961); trophoblast has also been seen in the blood from uterine veins (Douglas, Thomas, Cullen and Morris, 1959), and very rarely chorionic villi may be seen as emboli (Bardawil and Toy, 1959).

Experimental trophoblast emboli evoke no tissue reaction in the lung nor is thrombosis a feature (Park, 1958), suggesting that whilst placental tissue is a rich source of thromboplastin, detached trophoblastic cells do not possess sufficient activity to initiate local thrombosis or that inhibitory mechanisms may be operating. The demonstration of fibrinolytic activity in pulmonary veins (Todd, 1959), but not in placental tissue (Beller, Goessner and Herschlein, 1962) suggests some local pulmonary mechanism.

On rare occasions giant trophoblastic emboli have caused death in both normal pregnancy (Marcuse, 1954) and in hydatidiform mole (Hughes, 1930; Trotter and Tieche, 1956). The syndrome of pulmonary hypertension due to repeated tumour emboli from chorion carcinoma is now well known.

\section{Predisposing factors}

In most recorded cases to date generally accepted predisposing factors (heart disease, anæmia, post-operative states, prolonged bed rest, trauma or neoplasm) have been absent. Multiparity, multiple pregnancy and preeclampsia have been more commonly associated than primiparity. Thrombophlebitis precedes embolism in the majority of cases but the clinical evidence of leg vein involvement is sometimes delayed; recurrence of thrombophlebitis seems likely in subsequent pregnancies. There may be a racial or geographical factor, embolism being rare in Asians in Asia; embolism is exceedingly rare in the lower animals. While thrombophlebitis is common in pregnancy it may also be a presenting sign in systemic infections, blood dyscrasias and collagen diseases (Barker, 1936a; Miller and Daley, 1946). Superficial thrombophlebitis failing to respond to phenylbutazone is a sinister sign suggesting the Trousseau phenomenon (Stein, 1955). There is no convincing evidence to date that hormone preparations play any part in the genesis of thromboembolism in pregnancy.

\section{Case Reports}

Case No. 1

Mrs. M.M., aged 28 years, a primigravida married for six years, had been attending her general practitioner for ante-natal care. All went well until early June 1959, when at the twenty-eighth week of gestation she developed pain, swelling and tenderness of the right calf associated with prominent tender veins. Thrombosis with phlebitis was diagnosed and domiciliary treatment with poultices, bed rest, supportive dressings and oral penicillin was instituted. She had had no previous illness although she was subject to recurrent epistaxis. Satisfactory clinical resolution appeared to occur over the next week and she became ambulant again.

On the 13th July she suddenly developed pleuritic pain below the right breast and became dyspnœic Pleurisy was diagnosed but as her condition begaro to deteriorate hospital admission was sought on 15 th July.

On Examination in the ambulance by the author she was a well-covered young woman who appeared in danger of imminent death. Her colour was ashen, profuse sweating was present, the radial pulse was impalpable and severe dyspnœea was present. It was immediately apparent that marked deterioration had occurred during the ambulance journey. Administration of oxygen and the adoption of the supine position produced considerable relief. At this time there was no clinical evidence of leg vein thrombosis. Impaired movement, dullness to percussion, decreased breath and voice sounds were elicited from the right lower chest. Central cyanosis was present, the radial pulse was now palpable, regular, 110 per minute, B.P. $110 / 50 \mathrm{~mm}$. Hg.; she was apyrexial but slight finger clubbing was noted. The peripheral pulses were present, equal and not delayed, there was no evidence of pulmonary œdema, no evidence of preexisting cardiac or respiratory disease was elicited and no cervical emphysema was detected. Despite the minimal changes in the ECG it was felt that she had had a major episode of pulmonary embolism (Fig. 1), and immediate treatment consisted of continuous oxygen, six-hourly heparin and powerful analgæsics as required to reduce pain and allow deeper respirations. A course of systemic tetracycline was commenced.

Investigations: WBC 15,700/cu. mm.; ESR (Westergren) $78 \mathrm{~mm}$./hr., SGOT 25 units, SGPT 20 units per $\mathrm{ml}$. The fundus uteri corresponded in height to a pregnancy of 34 weeks, the fotal position was right occipito-anterior, movements were active and the heart was easily heard.

On this regime she gradually improved until 20th July when there was a further attack of overt

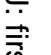
然 政

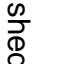

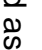
$\overrightarrow{0}$ 


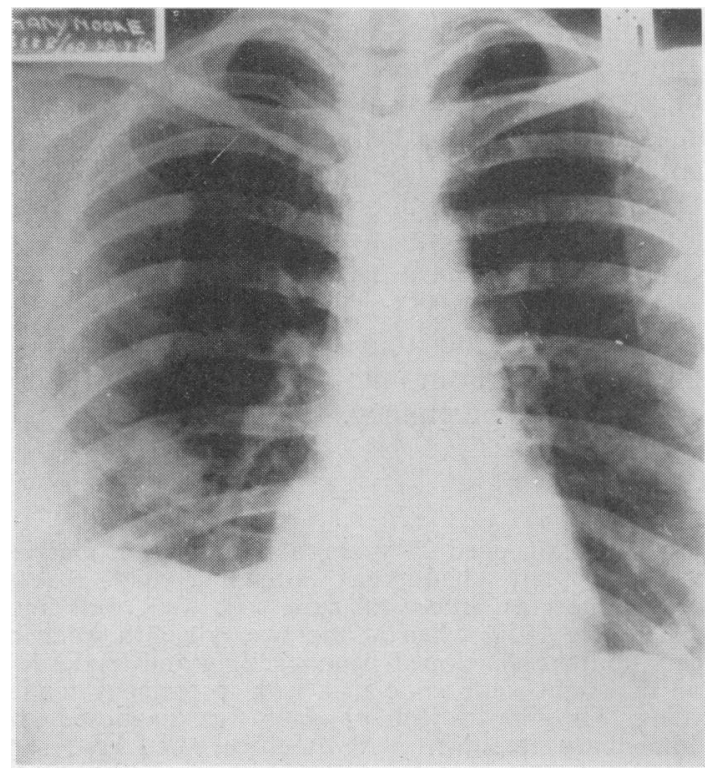

Fig. 1.-Case 1 .

embolism which again rendered her state critical. Subsequently however, on the same regime, she made rapid progress, ambulation and oral anticoagulant therapy being introduced and she was allowed home being seen weekly for review. On 17th August a further episode of embolism caused her readmission and the reinstituting of heparin therapy by repeated intravenous injection. There was now a right paravertebral systolic bruit which was attributed to stenosis of a large branch of the right pulmonary artery consequent on the previous attacks of embolism. Again there was gradual improvement and on 19th September clear amniotic fluid was removed following the passage of a Drew-Smythe catheter. Labour began six hours after this operation and progressed normally. No heparin was administered following the onset of labour and no attempt at heparin reversal was made. Oxygen was given by face mask to relieve cyanosis which was at times severe. After a first stage of six and a quarter hours, a spontaneous delivery of a normal living female infant took place (weight 5 lbs. 14 ozs., length 19 inches, head circumference $12 \frac{1}{2}$ inches). The second stage had lasted sixty five minutes and twenty five minutes later a normal placenta complete with membranes was delivered. There was no retroplacental clot and the total blood loss was within normal limits.

Oral phenindione was commenced twelve hours after delivery, breast feeding was not permitted and ambulation was begun three days after delivery. Lochia persisted for two weeks and was normal in appearance and volume. By the 26th September the chest was clinically clear although the bruit was still faintly audible on deep inspiration. She was allowed home on 13th October and continued normal progress as an out-patient still taking phenindione. Towards the end of November she began to feel unwell, had attacks of shivering and on 28th had a profuse epistaxis. By 30th November her condition was again serious (Temp. $102^{\circ}$, rapid shallow respirations, cyanosis, increased clubbing, and thick yellow sputum) and she was thought to have an aspiration pneumonia. Persistent epistaxis which was draining into the pharynx ceased after the withdrawal of phenindione (at no time had the one-stage prothrombin time exceeded twice the control value). Swinging pyrexia and amphoric breath sounds in the right lower lobe suggested pulmonary abscess. की Following surgical advice a prolonged course of $\bar{O}$ antibiotic treatment ensued with the gradual abatement of fever and sputum. Recovery was however further complicated by the development of a left iliofemoral thrombosis; this subsided rapidly following a heparin infusion and her return to normal activity was unimpeded. Three years later she remains in good health. During the period described no adverse features were discovered in the baby.

\section{Case No. 2}

A woman collapsed suddenly in a large store. On arrival at hospital she was found to be dead, but the uterus which was distended to a level between the umbilicus and the xiphisternum contained a live fœtus. Post-mortem cæsarean section was performed and the baby obtained alive although death followed six hours later.

Necropsy. The body was obese, measuring 5 feet 6 inches in height and weighing 18 stones $3 \frac{1}{2} \mathrm{lbs}$. The right lower limb was thicker than the left but there was no pitting cedema. Internally thrombus was present in the right common iliac vein and in the right femoral vein. Portions of the thrombus were less adherent than others and some portions appeared to have become detached. An impacted thrombus was present in the left main pulmonary artery? A benign colloid goitre was present, and the uterus contained many large, soft, sub-serous fibroids show ing lymphangiomatous degeneration.

Histological examination of the thrombus con firmed its nature and the absence of decidua or trophoblast.

\section{Discussion}

The diagnosis of ante-partum pulmonary embolism is rarely made, but when characteristic symptoms and signs occur should present little difficulty. Atypical presentations such as 'pleurisy' (as in Case 1), 'pneumonia', cardiac failure, renal failure, progressive fatigue, syncope and hypotensive episodes occasionally cause confusion (Sevitt and Gallagher, 1961). Rarely pulmonary embolism presents so as to resemble bacterial endocarditis, gastrointestinal disease or cerebro-vascular disorder (Hamilton and Thompson, 1963). Pulmonary artery thrombosis rarely arises in the absence of preceeding cardiac, respiratory or general medical disease (e.g. blood dyscrasia).

Cardiac infarction occurs in pregnancy (Magner, 1960) and is sometimes difficult to distinguish from massive pulmonary embolism (Wood, 1956). Shock, severe chest pain, fever, leukocytosis, and an elevated sedimentation rate are common findings in both conditions, the latter also being elevated in normal pregnancy. High levels of transaminase activity 
may be found in both and in the early difficult stage lactic dehydrogenase activity may be more helpful.

Evidence of right ventricular stress is provided by the electrocardiogram, but changes may not develop for several days. Serial records are therefore imperative in doubtful cases. Furthermore in pregnancy there is usually a prominent $S$ wave in lead $I$, and a $Q$ in lead III which is associated with an inverted T wave, changes due to the rotation of the heart. When pulmonary embolism sufficient to cause right ventricular stress occurs, sinus tachycardia, low voltages and similar changes to those of normal pregnancy are seen in standard leads. The $\mathbf{Q}$ wave in lead III being due to rotation is not reflected in aVF. Occasionally tall peaked $\mathbf{P}$ waves are seen in lead II. The præcordial leads show inverted $\mathrm{T}$ waves in $\mathrm{V}_{1^{-3}}$ or even further when there is much rotation. These changes are not dissimilar to those of posterior myocardial infarction, transient ST segment elevations in leads III and aVF being seen in both occasionally. Skiagrams show variable evidence of infarction but are often of little value in the early stages. Dissecting aneurysm (Schnitker and Bayer, 1944), ruptured osophagus (Kennard, 1950), spontaneous pneumothorax, and acute pulmonary œedema (Szekely and Snaith, 1957) are distinguished by their characteristic clinical features.

In Case 1 there was no known previous medical abnormality and no signs of chronic disease were elicited on physical examination. The typical appearance of the patient when first seen with the history of thrombophlebitis three weeks previously immediately suggested the diagnosis of thrombogenic pulmonary embolism. No retrospective evidence in support of alternative diagnosis was obtained.

With general supportive measures alone both fotal and maternal mortality rates are alarmingly high. Shock occasioned by pulmonary embolism may be counteracted by pressor amines as first shown by Wolff (1954), and the successful use of this measure in these circumstances during pregnancy was reported by Sibthorpe (1955). Corticosteroids, if used, would probably also need to be given during labour and to the newborn.

Even when there is an obvious thrombotic ite in the legs, and although success has been dttributed to venous surgery (e.g. Adamson, Weaver and Jaimet, 1950 case 2), proximal ligation gives no guarantee of success since the embolic focus may be elsewhere. Inferior vena caval ligation is attended by considerable dangers (Aird, 1958) and might present difficulties in late pregnancy. Paravertebral sympathetic block to relieve spasm is contraindicated in the course of anticoagulant treatment owing to the very real risk of retroperitoneal hæmorrhage (Lilly and Lee, 1949).

There is now convincing evidence that properly controlled anticoagulant therapy is a major advance in treatment. Previously pulmonary embolism in pregnancy had been attended by high mortality variably assessed as from $15 \%$ (Mansell, 1952) to $60 \%$ (Ullery, 1954). The use of anticoagulant drugs has reduced maternal mortality to very low levels but there exists a hazard to the foetus. In the newborn the coagulation mechanism is deficient and in prematurity this disturbance is more marked. Since coumarin-indanedione drugs act on the liver serious coagulation defects might be expected if these drugs pass the placental barrier. Schofield (1924) showed that the calves of cows which had fed on spoiled sweet clover developed fotal hæmorrhages, and Quick (1946) and Kraus (1949) showed that transplacental passage of dicoumarol occurred (in dogs and rabbits respectively). At least twelve cases of fœetal hæmorrhage in man are recorded and other unrecorded cases are known to the author.

In the first reported case (von Syndow, 1947), treated in the last month of pregnancy, severe cerebral and subcutaneous foetal hæmorrhages were present. Quenneville, Barton, McDevitt and Wright (1959) described three cases in two of which the maternal one-stage prothrombin time was depressed below presently acceptable levels, but even when this test shows less than accepted therapeutic levels foetal hæmorrhage has still occurred. In the presence of cardiac failure increased sensitivity to these drugs is common (Owren, 1954). Mahairas and Weingold (1963) using warfarin sodium in a patient with cardiac failure of rheumatic origin noted the prothrombin time to be 'labile' and after' thirteen days' treatment fotal death occurred. Thymic and retroplacental hæmorrhages were found at autopsy. Further examples are those of Sachs and Labate (1949) and Gordon and Dean (1955), the latter authors recommending the use of the two-stage prothrombin time test as a more adequate procedure. Due to the multiple defect produced by the coumarinindanedione drugs a test which measures this overall effect might be deemed more advisable in pregnancy (e.g. "Thrombotest").

Apart from the single case of Mahairas and Weingold (1963) retroplacental hæmorrhage has not been a feature of anticoagulant treatment 
in pregnancy, several series now being available, some of them admittedly small (Yahr, Reich and Eggers, 1945; Logan, O'Driscoll and O'Donoghue, 1951; Mansell, 1952). Barnes and Ervin (1946) showed that excessive bleeding is not a feature of the puerperium, during anticoagulant treatment and this is now common experience. Although labour has been allowed to proceed during full anticoagulant dosage it would seem wiser to withhold treatment during labour and delivery, as in Case 1.

No fœtal hæmorrhage has been recorded attributable to the use of heparin during pregnancy, possibly due to its high molecular weight-about 20,000 (Reynolds, 1949). The onset of heparin action is rapid, the effect profound, rapid antagonists are available and transplacental passage is unknown. Coumarinindanedione drugs are slower in onset, their effect is less profound on the maternal system, reversal is accomplished less easily and takes longer, and transplacental passage is well recognised. Severe anaphylactic reactions to heparin are now exceedingly rare whereas the number of reported incidents with oral anticoagulants is constantly growing and many of these are often fatal. In the absence of accepted contra-indications to anticoagulant therapy, or in the situation under discussion where these risks are outweighed by the danger of further fatal embolus, anticoagulant treatment in the antepartum period should be with repeated intravenous doses of heparin. (Six-hourly doses of the order of 10,000 units require no supervision of the clotting mechanism in the absence of shock; if a continuous heparin infusion is set up then the clotting mechanism should be monitored either by the whole blood clotting time or by the quicker and more reliable thrombin clotting time. In either test the therapeutic ratio in overt pulmonary embolism should be nearer three than two-Wood, 1956).

Post-partum anticoagulant therapy with the oral type of anticoagulant drug must be continued for an extended period in an attempt to prevent the development of subacute thromboembolic pulmonary hypertension (Wood, 1956). A period of at least one year has been recommended for this phase of management, but in Case 1 the danger of further epistaxes (to which she was particularly prone) and repeated pneumonic episodes with further lung damage were thought to outweigh any advantage to be gained from long term treatment. Three years after delivery she remains in good health.

The possible place of newer anticoagulant drugs and thrombolytic therapy has not been discussed.

At a recent Scientific Session of the Roya $\stackrel{\mathbb{R}}{2}$ College of Obstetricians and Gynæcologists this: problem received only passing mention and the? impression was gained that pulmonary embo을 lism is a result of putting patients to bed. A듬 recent review of the causes of sudden death in apparently healthy people in Philadelphis suggests that there may be other factors at work in obstetric patients; five cases of fataL pulmonary embolism were discovered in women in the first trimester of pregnancy $\vec{\omega}$ (Breckenridge and Ratnoff, 1964). In none of these cases were any unusual element present in the emboli (Breckenridge, 1964).

\section{Summary}

Two new cases of ante-partum thrombo embolism are reported, a brief survey of theo pathogenesis of this condition is made with special reference to pregnancy and the problems of anticoagulant treatment are discussed ${ }_{T}$ Heparin is at present thought to be the agen $\mathbb{C}$ of choice in this situation.

I am indebted to Mr. H. Roberts for permission to report the clinical details of Case 1 , and to $\mathrm{Br} \overrightarrow{\mathrm{Br}}$ G. Billington, H. M. Coroner for the City Birmingham, and Dr. D. A. Heath for allowing 魷 to include Case 2.

To both Mr. H. Roberts and Dr. C. W. Taytoro I owe sincere thanks for their advice, criticism and encouragement during the preparation of this papero

\section{REFERENCES}

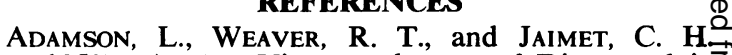
(1950): A New View on the use of Dicumarol in̄ the Pregnant Patient, Amer. J. Obstet. Gynec., 59, 498.

AIRD, I. (1958): Companion in Surgical Studies London: E. \& S. Livingstone.

ATtwoOd, H. D., and PARK, W. W. (1961): Embolism? to the Lungs by Trophoblast, J. Obstet. Gynaec? Brit. Emp., 68, 611.

BARDAWIL, W. A., and ToY, B. L. (1959): The Natural History of Choriocarcinoma; Problems of Immunity and Spontaneous Regression, Ann. N.Y Acad. Sci., 80, 197.

BARKER, N. W. (1936a): Thrombophlebitis Complicat-을 ing Infections and Systemic Diseases, Proc. Mayo Clin., 11, 513.

BarneS, A. C., and ERvin, H. K. (1946): The Effects. of the Anti-coagulants on Post-partum Bleeding $N$ Surg., Gynec., Obstet., 83, 528.

Beller, F. K., Goessner, W., and Herschlein, H. J N (1962): Tissue Activator of the Fibrinolytic System in Placental Tissue, Obstet. Gynec., 20, 117.

BRECKENRIDGE, R. T. (1964): Personal communication , and RATNOFF, O. (1964): Pulmonary Embolisneo and Unexpected Death in Supposedly Normal Per $\frac{\bar{\phi}}{\varnothing}$ sons, New Engl. J. Med., 270, 298.

BurWell, C. S., StrayhorN, W. D., Flickinger, D.; CoOlette, M. B., Bowerman, E. P., and KenNedy, J. A. (1938): Circulation during Pregnancy, Arch, intern. Med., 62, 979. 
Douglas, G. W., Thomas, L., Carr, M., Cullen, N. M., and MorRIS, R. (1959): Trophoblast in the Circulating Blood during Pregnancy, Amer. J. Obstet. Gynec., 78, 960.

GordoN, R. R., and DEAN, T. (1955): Foetal Deaths from Anti-coagulant Therapy, Brit. med. J., ii, 719.

Hamilton, M., and ThompsoN, E. N. (1963): Unusual Manifestations of Pulmonary Embolic Disease, Postgrad. med. J., 49, 348.

Hughes, J. E. (1930): A Case of Hydatidiform Mole with Multiple Small Syncytial Infarctions in the Lungs, Proc. roy. Soc. Med., 23, 1157.

KraUS, A. R. (1949): Danger of Dicumarol Treatment in Pregnancy, Amer. med. Ass., 139, 758.

LILlY, G. D., and LEE, R. M. (1949): Complications of Anti-coagulant Therapy, Surgery, 26, 957.

LogaN, P. J., O'Driscoll, A. M., and O'Donoghue, R. F. (1951): Thrombophlebitis during Pregnancy, J. Obstet. Gynac. Brit. Emp., 58, 433.

MAGNER, D. (1961): Coronary Occlusion in Labour, ibid, 68, 128.

Mahairas, H. M., and Weingold, A. B. (1963): Fetal Hazard with Anti-coagulant Therapy, Amer. J. Obstet. Gynec., 85, 234.

Mansell, R. V. (1952): Ante-partum Dicumarol Therapy, ibid, 64, 155 .

MarCuSE, P. M. (1954): Pulmonary Giant Cell Syncytial Embolism, Obstet. Gynec., 3, 210.

Miller, H. G., and DALeY, R. (1946): Clinical Aspects of Polyarteritis Nodosa, Quart. J. Med., 15, 255

O'Brien, J. R. (1959): Some Effects on Coagulation of Erythrocytes and Other Cells, J. clin. Path., $12,45$.

O'Neill, J. F. (1947): The Effects on Venous Endothelium of Alterations in Blood Flow through the Vessels in Vein Walls, and the Possible Relation to Thrombosis, Ann. Surg., 126, 270.

OWREN, P. A. (1954): Long-term Anti-coagulant Therapy in Coronary Artery Disease, Schweiz. med. Wschr., 84, 822.

PARK, W. W. (1958): Experimental Trophoblastic Embolism of the Lungs, J. Path. Bact., 75, 257.

Poole, J. C. F. (1959): A Study of Artificial Thrombi Produced by a Modification of Chandler's Method, Quart. J. exp. Physiol., 44, 377.

QUENNEVILle, G., BARTON, B., MCDEVITT, E., and WRIGHT, I. (1959): The Use of Anti-coagulants for Thrombophlebitis during Pregnancy, Amer. J. Obstet. Gynec., 77, 1135.

Quick, A. J. (1946): Experimentally Induced Changes in the Prothrombin Concentration of the Blood;
III. Prothrombin Concentration of New-born Pups of a Mother given Dicumarol before Parturition, J. biol. Chem., 164, 371.

REYNOLDS, S. R. M. (1949): Physiology of the Uterus, Ed. 2, p. 389, New York: Paul Hoeber.

SACHS, J. J., and LABATE, J. S. (1949): Dicumarol in the Treatment of Ante-natal Thrombo-embolic Disease, Amer. J. Obstet. Gynec., 57, 965.

SCHNITKER, M. A., and Bayer, C. A. (1944): Dissecting Aneurysm of the Aorta in Young Individuals Particularly in Association with Pregnancy, Ann. intern. Med., 20, 486.

SCHOFIELD, F. W. (1924): Damaged Sweet Clover; the Cause of a New Disease in Cattle simulating Hæmorrhagic Septicæmia and Blackleg, J. Amer. vet. Med. Ass., 64, 553.

SevitT, S., and Gallagher, N. G. (1961): Venous Thrombosis and Pulmonary Embolism, Brit. J. Surg., 48, 473.

SiBTHORPE, E. (1955): Ante-partum Thromboembolism, Brit. med. J., ii, 1063.

STEIN, I. D. (1955): Further Observations on the Treatment of Superficial Thrombophlebitis with Phenylbutazone, Circulation, 12, 833.

voN SYNDOW, G. (1947): Hypoprothrombinemio ch Hjärnskada Hosbarn till Dikumarin Behandlad Moder, Nord. Med., 34, 1171.

SzEKELY, P., and SNAITH, S. (1957): Acute Pulmonary Oedema in Pregnancy, J. Obstet. Gynac. Brit. Emp., 54, 840.

ToDD, A. S. (1959): The Histological Localisation of Fibrinolysin Activator, J. Path. Bact., 78, 281.

TrotTER, R. F., and Tieche, H. L. (1956): Maternal Death due to Pulmonary Embolism of Trophoblastic Cells, Amer. J. Obstet. Gynec., 71, 1114.

Ullery, J. C. (1954): Thromboembolic Disease Complicating Pregnancy and the Puerperium, ibid, 68, 1243.

WITTE, S., and SCHRICKER, K. T. (1958): Experimentelle Untersuchungen über das Verhalten des Thrombocyten im Kreislauf, Klin. Wschr., 36, 1119.

WolfF, F. W. (1954): Shock due to Pulmonary Embolism, Lancet, ii, 72.

Wood, P. (1956): Diseases of the Heart and Circulation, London: Eyre and Spottiswoode.

Wright, H. P., OSBORN, S. B., and EDMUNDS, D. G. (1950): Changes in the Rate of Flow of Venous Blood in the Leg during Pregnancy, Measured with Radioactive Sodium, Surg. Gynec. Obstet., 90, 481.

YAHR, M. D., REICH, C., and EgGERS, C. (1945): Treatment of Thrombophlebitis, Surg. Gynec. 